\title{
The Most Fatal 2014 Outbreak of Ebolavirus Disease in Western Africa
}

\author{
Haradhan Kumar Mohajan* \\ Faculty of Business Studies, Premier University, Chittagong, Bangladesh \\ *Corresponding author: haradhan1971@gmail.com
}

Received September 05, 2014; Revised September 25, 2014; Accepted September 27, 2014

\begin{abstract}
The first Ebolavirus diseases outbreak was in Zaire (now Democratic Republic of the Congo) in 1976. The 2014 Ebola outbreak is the deadliest and the largest Ebola outbreak in history and the first in western Africa. More than 2,746 people had died from this outbreak. The disease is a severe, often fatal in humans and nonhuman primates. It cannot naturally transmit through the air, water or food and can be spread by direct contact with blood and secretions of the infected patients. At present there is no standard treatment for Ebolavirus diseases; only supportive therapy is available. Hence prevention is the best way by not traveling to areas where the virus is found. The paper represents an elementary idea of Ebolavirus diseases to create consciousness of the disease among common people.
\end{abstract}

Keywords: Ebolavirus, Africa, WHO, CDC

Cite This Article: Haradhan Kumar Mohajan, "The Most Fatal 2014 Outbreak of Ebolavirus Disease in Western Africa.” American Journal of Epidemiology and Infectious Disease, vol. 2, no. 4 (2014): 101-108. doi: 10.12691/ajeid-2-4-4.

\section{Introduction}

Ebolavirus disease (EVD) or Ebola hemorrhagic fever (EHF) is a viral human disease caused by the Ebolavirus that results in nonspecific symptoms early in the disease and often causes internal and external bleedings as the disease progresses. Ebola hemorrhagic fever is considered one of the most lethal viral infections and the mortality rate is very high during outbreaks. Since 1976 EVD outbreaks have appeared sporadically in central and western Africa, for example, in Gabon, The Democratic Republic of the Congo (DRC), Sudan, The Ivory Coast, Uganda, Guinea, Sierra Leone, Nigeria and Liberia. There have been 26 confirmed outbreaks of the disease since 1976.

2014 Ebola outbreak has spread like wildfire and causes an alarming worldwide. The first cases were reported from Guéckédou, a forested region of south-eastern Guinea near the border with Liberia and Sierra Leone. It is considered the deadliest and the largest Ebola outbreak in history and the first in western Africa [11].

On 8 August 2014, the EVD outbreak in western Africa was declared in Geneva by the WHO to be a 'Public Health Emergency of International Concern (PHEIC)', because it was determined to be an 'extraordinary event' with public health risks to other States. After discussion and deliberation on the information provided, the committee advised that [46]:

- The Ebola outbreak in western Africa constitutes an 'extraordinary event' and a public health risk to other States.
- The possible consequences of further international spread are particularly serious in view of the virulence of the virus, the intensive community and health facility transmission patterns, and the weak health systems in the currently affected and most atrisk countries.

- A coordinated international response is deemed essential to stop and reverse the international spread of Ebola.

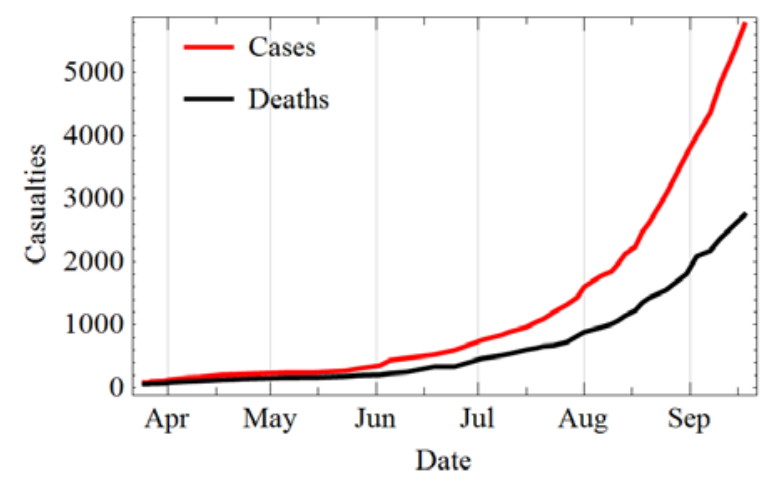

Figure 1. Ebola cases and deaths in 2014 outbreak. Source: [51]

EVD can spread from country to country when people travel. The disease infections can only be confirmed through laboratory testing.

On 17 September 2014, WHO expressed that more than 2,746 people had died and 5,762 confirmed or probable cases in West Africa's 2014 Ebola outbreak (Figure 1). WHO also warned that at least $\$ 600$ million is needed to fight the virus, and more than 20,000 people could be infected before the outbreak is brought under control [50]. 


\section{Types of the Ebolavirus}

It is a severe, often fatal disease in humans and nonhuman primates, such as monkeys, gorillas, and chimpanzees. Sometimes EVD affects in domestic pigs. EHF is caused by infection with a virus of the family Filoviridae, genus Ebolavirus. There are 5 identified subspecies of Ebolavirus. Four of the 5 subspecies i) Ebolavirus (Zaire ebolavirus), EBOV ii) Sudan virus (Sudan ebolavirus), SUDV, iii) Bundibugyo virus (Bundibugyo ebolavirus), BDBV and iv) Taï Forest virus (Taï Forest ebolavirus), TAFV, have caused disease in humans. The $5^{\text {th }}$ Reston virus (Reston ebolavirus), has caused disease in nonhuman primates, but not in humans [10].

First three ebolavirus have been associated with large Ebolavirus disease outbreaks in Africa, whereas $4^{\text {th }}$ has not. Among the 5 subspecies Zaire ebolavirus is the most dangerous because it has the highest case fatality rate up to $90 \%$ [24]. Sudan ebolavirus is believed to have broken out first among cotton factory workers in Nzara, south Sudan in 1976 with fatality rates 50\% to 68\% [17]. Taï Forest ebolavirus was first discovered among chimpanzees from the Taï Forest in Ivory Coast, Africa, in
1994 [39]. On 24 November 2007, the Uganda Ministry of Health confirmed an outbreak of Bundibugyo ebolavirus in the Bundibugyo district [42]. Reston ebolavirus discovered in Reston, Virginia and it has been found in nonhuman primates in Pennsylvania, Texas and Siena, Italy [7].

\section{History of Ebolavirus}

The first Ebolavirus species were discovered in Sudan and the Democratic Republic of the Congo (DRC) near the tributary Ebola River valley (in the northern Congo basin of central Africa) during an outbreak in Zaire in 1976 [6]. Since 1976 the mortality rates varied from 50 to $90 \%$ (Table 1). It is not clear why some patients can survive and others die from this disease, but patients who die usually have a poor immune response to the virus. The natural host for Ebolavirus is yet unknown. At present there is no antiviral therapy or vaccine that is effective against Ebolavirus infection in humans. Hence it has not been possible to implement skillful techniques to control or eliminate the disease at present situation [36].

Table 1. EVD outbreaks since 1976

\begin{tabular}{|c|c|c|c|c|c|}
\hline Year & Virus & Geographic Location & Human Deaths & Cases & CFR (case-fatality risk) \\
\hline 1976 & SUDV & Juba, Madrid, Nzara, and Tembura, Sudan & 151 & 284 & $53 \%$ \\
\hline 1976 & EBOV & Yambuku, Zaire & 280 & 318 & $88 \%$ \\
\hline 1977 & EBOV & Bonduni, Zaire & 1 & 1 & $100 \%$ \\
\hline 1979 & SUDV & Nzara, Sudan & 22 & 34 & $65 \%$ \\
\hline 1988 & EBOV & Porton Down, United Kingdom [laboratory accident] & 0 & 1 & $0 \%$ \\
\hline 1994 & TAFV & Tai National Park, Cote d'Ivoire & 0 & 1 & $0 \%$ \\
\hline 1994-1995 & EBOV & Woleu-Ntem and Ogooue-Ivindo Provinces, Gabon & 32 & 52 & $62 \%$ \\
\hline 1995 & EBOV & Kikwit, Zaire & 245 & 317 & $77 \%$ \\
\hline 1996 & EBOV & Mayibout 2, Gabon & 21 & 31 & $68 \%$ \\
\hline 1996 & EBOV & Sergiyev Posad, Russia [laboratory accident] & 1 & 1 & $100 \%$ \\
\hline 1996-1997 & EBOV & $\begin{array}{l}\text { Ogooue-Ivindo Provinces, Gabon; Cuvette-Ouest } \\
\text { Department, Republic of the Congo }\end{array}$ & 46 & 62 & $74 \%$ \\
\hline $2000-2001$ & SUDV & Guku, Mbarara, and Masindi Districts, Uganda & 224 & 425 & $53 \%$ \\
\hline 2001-2002 & EBOV & $\begin{array}{l}\text { Ogooue-Ivindo Provinces, Gabon; Cuvette-Ouest } \\
\text { Department, Republic of the Congo }\end{array}$ & 97 & 124 & $78 \%$ \\
\hline 2002 & EBOV & $\begin{array}{l}\text { Ogooue-Ivindo Provinces, Gabon; Cuvette-Ouest } \\
\text { Department, Republic of the Congo }\end{array}$ & 10 & 11 & $91 \%$ \\
\hline 2002-2003 & EBOV & $\begin{array}{l}\text { Cuvette-Ouest Department, Republic of the Congo; } \\
\text { Ogooue-Ivindo Provinces, Gabon }\end{array}$ & 128 & 143 & $90 \%$ \\
\hline 2003-2004 & EBOV & Cuvette-Ouest Department, Republic of the Congo & 29 & 35 & $83 \%$ \\
\hline 2004 & EBOV & Koltsovo, Russia [laboratory accident] & 1 & 1 & $100 \%$ \\
\hline 2004 & SUDV & Yambio County, Sudan & 7 & 17 & $41 \%$ \\
\hline 2005 & EBOV & Cuvette-Ouest Department, Republic of the Congo & 9 & 11 & $82 \%$ \\
\hline 2007 & EBOV & $\begin{array}{l}\text { Kasai Occidental Province, Democratic Republic of } \\
\text { the Congo }\end{array}$ & 186 & 264 & $71 \%$ \\
\hline $2007-2008$ & BDBV & Bundibugyo District, Uganda & 39 & 116 & $34 \%$ \\
\hline 2008-2009 & EBOV & $\begin{array}{l}\text { Kasai Occidental Province, Democratic Republic of } \\
\text { the Congo }\end{array}$ & 15 & 32 & $47 \%$ \\
\hline 2011 & SUDV & Luweero District, Uganda & 1 & 1 & $100 \%$ \\
\hline 2012 & SUDV & Kibaale District, Western Uganda & 17 & 24 & $71 \%$ \\
\hline 2012 & BDBV & $\begin{array}{l}\text { Orientale Province, Democratic Republic of the } \\
\text { Congo }\end{array}$ & 36 & 77 & $47 \%$ \\
\hline 2014 & EBOV & Guinea, Sierra Leone, Liberia, Nigeria & 2,746 & 5,762 & $47.7 \%$ \\
\hline
\end{tabular}

The first outbreak of Ebola-Sudan infected in Sudan from June to November 1976. More than 284 people (213

in Maridi, 67 in Nzara, 3 in Tembura and 1 in Juba), with a mortality rate of $53 \%$ [40]. A few months later 
(September to October), the second Ebolavirus (EbolaZaire) emerged from Yambuku and northern Zaire, with the highest mortality rate of any of the Ebolaviruses (88\%), infected 318 people [41]. In 1979 between 30 July and 7 October 34 cases of EVD (with 22 fatal) occurred among 5 families in rural district of southern Sudan. Between 2 to 5 August a family of 4 members in Nzara is infected with EVD but after admission in hospital all died. In the late August a second family of 20 members with EVD was admitted in hospital but 13 members of that family with 2 nurses who took care of them died. A total 5 families were infected with EVD between 30 July and 7 October, 1979 [1].

The Ebolavirus (Ebola Reston) was first identified in 1989 when infected monkeys were imported into Reston and Virginia of the USA to research facilities, from Mindanao in the Philippines, very few people who were infected with this virus and never developed EHF [22]. The Ebolavirus (Ebola Cote d'Ivoire) was discovered in 1994 when a female ethologist performing an autopsy on a dead chimpanzee from the Tai Forest, Cote d'Ivoire, accidentally infected herself during the autopsy [33].

The first outbreak of EHF due to Bundibugyo ebolavirus occurred in Uganda from August to December 2007. About 131 EHF cases (44 suspects, 31 probable and 56 confirmed) are identified and 39 died in that outbreak $[25,42]$.

Most outbreaks of the lethal strains of Ebola have occurred in Africa and mainly in small- or medium-sized towns. The largest outbreak to date is the ongoing "2014 western Africa Ebola outbreak", which is affecting four countries Guinea, Liberia, Sierra Leone and Nigeria. More than 2,746 people had died in 2014 outbreak (Table 1). The 2014 outbreak becomes complicated by a limited health workforce and particularly by misperceptions of the disease among some people living in affected regions $[9,50]$.

\section{Symptoms of EVD}

Common symptoms of Ebolavirus are; fever, myalgia, malaise, sore throat, weakness, severe headache, joint and muscle pain, diarrohea, vomiting, stomach pain, dehydration, dry and hacking cough, lack of appetite. Symptoms of Ebolavirus typically start two days to three weeks after contacting the virus. After 4 to 6 days, on average, Ebola symptoms can begin. More cases Ebolavirus infection runs its course within 14 to 21 days. The period between infection with the virus and the start of symptoms is called the incubation period [7].

After the infection progresses, patients experience severe bleeding and coagulation abnormalities, such as, gastrointestinal bleeding, rash, and a range of hematological irregularities, such as lymphopenia and neutrophilia. In the next step the virus damages the liver and impaired kidney and liver functions. Massive viremia is visible which leads to dispersed intravascular coagulopathy. Finally the Ebolavirus infects microvascular endothelial cells and compromises vascular integrity [14].

Some patients may experience rash, cough, red eyes, hiccups, chest pain, difficulty breathing, difficulty swallowing, internal and external bleedings, along with decreased functioning of the liver and kidneys. At this point, some people begin to have problems with bleeding inside and outside of the body. At the end state, the patients feel delirium, shock, seizures and coma, causes levels of blood-clotting cells to drop and finally died [44].

The patient fortunate enough to survive EHF still may have complications that may take many months to resolve. Survivors may experience weakness, fatigue, headaches, hair loss, hepatitis, sensory changes, and inflammation of organs. Death usually occurs during the $2^{\text {nd }}$ week of symptoms and is usually from massive blood loss. In pregnant women, abortion and heavy vaginal bleeding are common Ebola symptoms [10].

\section{Transmission of Ebolavirus}

From the outbreaks since 1976, it is observed that Ebolavirus cannot naturally transmit through the air, water or food. A person who has Ebola but has no symptoms cannot spread the disease. Ebolavirus can be spread by direct contact with blood and secretions (stool, urine, saliva, semen etc.) that remain on clothing, tissues, organs or other bodily fluids of dead or living infected persons and by syringes used to treat Ebola-infected patients. Those who take care of a sick person or bury someone who has died from the disease often get it. Men who have recovered from the disease can still transmit the virus through their semen for as long as 7 weeks after recovery from illness. Unsanitary conditions and lack of adequate medical supplies may cause the spread of the disease [15].

Health workers may be infected to the virus when caring for Ebola patients if they are not wearing personal protection equipment, such as gloves, when caring for the patients. In traditional burial ceremonies mourners come in direct contact with the dead body and can transmits the dieses [14].

The disease may be acquired upon contact with the skin or blood or bodily fluids of an infected animal, such as monkeys, gorillas, forest antelopes, chimpanzees or fruit bats and porcupines found ill or dead. Fruit bats are believed to carry and spread the virus without being affected i.e., the natural host for the virus. Particularly species of the fruit bats Hypsignathus monstrosus, Epomops franqueti and Myonycteris torquata, are considered possible natural hosts for Ebolavirus. If actually fruit bats are natural hosts for Ebolavirus then the geographic distribution of Ebolaviruses may overlap with the range of the fruit bats [47].

Reston ebolavirus has caused severe EVD outbreaks in macaque monkeys (Macaca fascicularis) farmed in Philippines and detected in monkeys imported into the USA in 1989, 1990 and 1996, and in monkeys imported to Italy from Philippines in 1992. Since 2008, Reston ebolavirus has been detected during several outbreaks of a deadly disease in pigs in People's Republic of China and Philippines [33].

It is not known yet how the viruses attack cells; it has been postulated that they produce proteins that suppress the immune system, allowing reproduction of virus to continue unrestricted. Eating of bushmeat of wild animals, including hoofed animals, primates and rodents are another cause of transmission of EVD [15]. 
However, Ebolavirus can be inactivated by ultra violate (UV) radiation, gamma irradiation, heating for 60 minutes at $60^{\circ} \mathrm{C}$ or boiling for 5 minutes. The virus is susceptible to sodium hypochlorite and disinfectants [31]. But it cannot be inactivated by freezing [13].

\section{Structure of Ebolavirus}

Ebolavirus is pleomorphic, negative-sense RNA (ribonucleic acid) whose genome organization is most similar to the Paramyxoviridae. The Zaire ebolavirus genome is $19 \mathrm{~kb}$ long, with 7 open reading frames encoding structural proteins are: NP, VP35, VP40, GP, VP30, VP24 and L [30,34].

The nucleoprotein (NP) is associated with the viral genome and assembles into a helical nucleocapside (NC) along with the polymerase cofactor (VP35), the transcription activator (VP30), and the RNA dependent RNA polymerase (L). The viral proteins that comprise the NC catalyze the replication and transcription of the viral genome $[3,28,29]$. A minor viral matrix protein, VP24 is needed for NC assembly [27]. When NP is co-expressed with VP24 and VP35, NC-like structures are formed in the cytoplasm which is morphologically identical from those seen in infected cells [4,5].

The GP open reading frame of Ebolavirus gives rise to two gene products, a soluble $60-70 \mathrm{kDa}$ protein and a full length $150-170 \mathrm{kDa}$ protein that inserts into the viral membrane [37]. The Ebolavirus GP is synthesized in a secreted or full length transmembrane form, and each gene product has distinct biochemical and biological properties [35]. The Ebolavirus GP contains a homologous hairpin structure so that a possible inhibitory peptide has been identified [38].

Electron micrographs of Ebolavirus show them to have the characteristic threadlike structure of a filovirus, VP30 is around 288 amino acids long (Figure 2). The virions are tubular in general form but variable in overall shape and may appear as the classic shepherd's crook or eyebolt, as a $U$ or a 6 , or coiled, circular, or branched; laboratory techniques, such as centrifugation, may be the origin of some of these formations. Virions are generally $80 \mathrm{~nm}$ in diameter with a lipid bilayer anchoring the glycoprotein which projects 7 to $10 \mathrm{~nm}$ long spikes from its surface. They may be $800 \mathrm{~nm}$ up to $1,000 \mathrm{~nm}$ long. In the center of the virion there is a structure called nucleocapsid, which is formed by the helically wound viral genomic RNA complexed with the proteins NP, VP35, VP30, and L. Virally encoded GP spikes $10 \mathrm{~nm}$ long and $10 \mathrm{~nm}$ apart are present on the outer viral envelop of the virion. Between envelope and nucleocapsid, the viral proteins VP40 and VP24 are located [16,23].

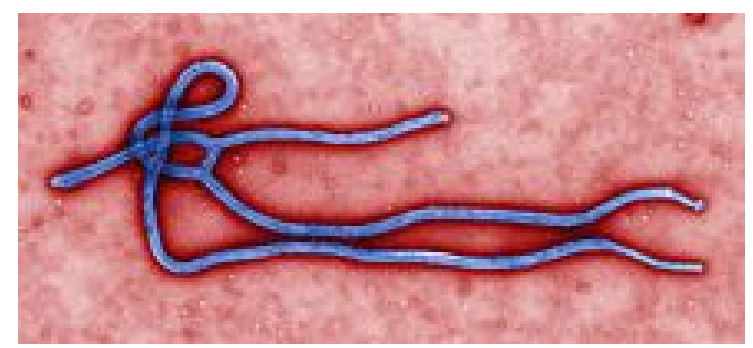

Figure 2. Electron micrograph of an Ebolavirus viron. Source: [51]

\section{Higher EHF Risk Regions and Persons}

At present all cases of illness or death have occurred in central and western Africa. The most EHF infected countries of Africa are; Guinea, Liberia, Sierra Leone, DRC, Gabon, South Sudan, Ivory Coast, Uganda, and South Africa. Health care providers, family members and friends of an infected individual are in high risk of EHF infection. Mourners who have direct contact with the bodies of the deceased as part of burial ceremonies are also in high risk of infection of the disease. Hunters in the rain forest who come into contact with dead animals found lying in the forest are also may infect with EVD [47].

\section{Diagnosis of EHF}

Diagnosing EHF in an individual who has been infected for only a few days is difficult, because the early symptoms, such as red eyes and a skin rash, are nonspecific to Ebolavirus infection. When these symptoms are seen then the patients are already infected with the disease. Doctors may test to rule out other diseases like cholera or malaria [8].

Diagnostic tests within a few days after symptoms begin are; antigen-capture enzyme-linked immunosorbent assay (ELISA) testing, IgM ELISA, antigen detection tests, serum neutralization test, polymerase chain reaction (PCR) and virus cultivation and biopsy samples. Later tests in disease course or after recovery are; IgM and IgG antibodies. Tests in retrospectively in deceased patients are; Immunohistochemistry testing, PCR and virus isolation. Samples from patients are extreme biohazard risk and testing should be conducted under maximum biological suppression conditions [8].

\section{Treatment of EHF}

At present there is no standard treatment for EHF; only supportive therapy is available. The preliminary treatments are; balancing the patient's fluids and electrolytes, maintaining their oxygen status, blood pressure and blood transfusions, and treating them for any complicating infections. Current therapy consists of maintenance of fluid and electrolyte balance and administration of blood and plasma to control bleeding. Treatment includes an experimental serum that destroys infected cells. Experimental treatment has been tested and proven effective in animal models but has not yet been used in humans [10].

Early recognition of Ebola is important for providing appropriate patient care and preventing the spread of infection. The infected patient needs to be isolated, and immediately contacted needs in local and state health departments [43].

\section{Prevention of EHF}

It is still unknown how exactly people are infected with EHF, so that prevention of it is more challenging. Because it is still unknown how exactly people are infected with EHF, there are few established primary prevention 
measures. The best way to avoid catching the disease is by not traveling to areas where the virus is found. Raising awareness among the people about the risk factors for Ebola infection and the protective measures individuals can take is another way to reduce human infection and death. People who have died from EVD should be promptly and safely buried [11].

If an outbreak is suspected, the premises should be quarantined immediately. Patients, health care providers and family members of the patients should use sodium hypochlorite or other detergents during washing of hands and other parts of the body to inactivate the virus. Regular hand washing is necessary after visiting patients in hospital, as well as after taking care of patients at home [21].

Burial or incineration of carcasses of animals is necessary to reduce the risk of animal-to-human transmission of EVD. Banning the movement of animals from infected farms to other areas can reduce the spread of the disease. Animals infected with Ebolavirus should be handled with gloves and other appropriate protective clothing and their meat should be thoroughly cooked before eating [49].

Health care providers must wear protective clothing, such as masks, gloves, full-body hazmat suits and goggles; they use infection-control measures, such as complete equipment sterilization and routine use of disinfectant; isolation of EHF patients from contact with unprotected persons when the blood or secretions of an infected patient is tested and provide treatment to the patients. Rooms of infected patients must not be sprayed with disinfectant which is dangerous and gives no benefit. Infectious waste should be removed periodically according to the advice of the EVD specialists [43].

Patients that are suspected or confirmed to have the disease should be isolated from other patients and treated by health workers using strict infection control precautions. Several vaccines of Ebolavirus are being tested, but none are available for clinical use [21].

\section{Response by WHO}

The WHO Strategic Action Plan for Ebola Outbreak Response is divided into two parts [43]:

- Immediate actions to support the three first EVD affected countries (Guinea, Liberia, and Sierra Leone).

- Interventions in neighboring at-risk countries to increase preparedness and prevent the occurrence of additional outbreaks.

Global Outbreak Alert and Response Network (GOARN) support to ongoing outbreak response interventions will be scaled-up. Estimated budget for response to the epidemic of EHF over 6 months (JulyDecember 2014) is given in Table 2:

Table 2. Response Plan for WHO and the Governments of Guinea, Sierra Leone and Liberia, July-December 2014: Source: [45]

\begin{tabular}{|c|c|c|c|c|c|c|c|c|}
\hline Item & $\begin{array}{l}\text { WHO Ebola Control } \\
\text { Center Conakry }\end{array}$ & $\begin{array}{l}\text { WHO } \\
\text { global }\end{array}$ & $\begin{array}{l}\text { WHO CO } \\
\text { Guinea }\end{array}$ & $\begin{array}{c}\text { WHO CO } \\
\text { Sierra } \\
\text { Leone } \\
\end{array}$ & $\begin{array}{l}\text { WHO CO } \\
\text { Liberia }\end{array}$ & $\begin{array}{l}\text { WHO CO } \\
\text { Nigeria }\end{array}$ & $\begin{array}{c}\text { Preparedness } \\
\text { neighboring } \\
\text { countries }\end{array}$ & Totals \\
\hline $\begin{array}{l}\text { Coordination, finance } \\
\text { and logistics }\end{array}$ & $2,224,294$ & $6,036,800$ & $1,132,599$ & $2,626,841$ & $2,180,560$ & 180,000 & 0 & $34,722,790$ \\
\hline $\begin{array}{l}\text { Epidemiology and } \\
\text { laboratory }\end{array}$ & 0 & $6,645,000$ & 102,964 & 238,804 & 198,233 & 180,000 & 0 & $16,338,624$ \\
\hline $\begin{array}{l}\text { Case management and } \\
\text { infection prevention } \\
\text { and control; } \\
\text { Psychosocial support }\end{array}$ & 0 & $6,295,000$ & 360,373 & 835,813 & 693,815 & 0 & 0 & $26,940,071$ \\
\hline $\begin{array}{l}\text { Social mobilization/ } \\
\text { Public Information }\end{array}$ & 0 & $1,425,700$ & 102,964 & 238,804 & 198,233 & 360,000 & 0 & $2,325,700$ \\
\hline Leadership & 0 & 600,000 & 102,964 & 238,804 & 198,233 & 360,000 & 0 & $1,500,000$ \\
\hline $\begin{array}{l}\text { Preparedness (Non- } \\
\text { affected countries and } \\
\text { countries at risk) }\end{array}$ & 0 & 900,000 & 0 & 0 & 0 & 225,000 & 884,800 & $2,009,800$ \\
\hline $\begin{array}{l}\text { Programme } \\
\text { Overheads 7\% }\end{array}$ & 155,701 & $1,533,175$ & 126,130 & 292,535 & 242,835 & 0 & 61,936 & $2,350,376$ \\
\hline $\begin{array}{l}\text { Total WHO global } \\
\text { plan action }\end{array}$ & $2,379,994$ & $23,435,675$ & 1,927,993 & $4,471,599$ & $3,711,908$ & $1,305,000$ & 0 & $37,232,169$ \\
\hline $\begin{array}{l}\text { Cost of preparedness } \\
\text { (potential } 8 \text { countries) }\end{array}$ & 0 & 0 & 0 & 0 & 0 & 0 & $7,573,888$ & 7,573,888 \\
\hline $\begin{array}{c}\text { Total WHO response } \\
\text { plan }\end{array}$ & 0 & 0 & 0 & 0 & 0 & 0 & 0 & $44,806,057$ \\
\hline
\end{tabular}

\section{Situation of 2014 Ebolavirus Outbreak in Africa}

The EHF epidemic was declared in Africa on 21 March 2014. WHO is committed to support all affected countries as well as the neighboring countries to bring the epidemic under control. WHO continues to monitor the evolution of the Ebola outbreak and engage with all actors from governments, technical partners, field operation partners, donor partners at local, region, and global level. More than 200 experts have been deployed in the three countries (Guinea, Liberia, and Sierra Leone) by WHO and GOARN partners, but more are needed [46,47].

By 22 August 2014, the WHO, in partnership with the Ministries of Health in Guinea, Sierra Leone, Liberia, and Nigeria reported 2,615 suspect and confirmed cases of EVD, including 1,528 laboratory-confirmed cases, and 1,427 deaths [11]. As of 17 September 2014, WHO and 
CDC reported a total of 5,762 suspected cases and 2,746 deaths $[12,50]$.

\subsection{Sierra Leone}

On 25 May 2014, the Government of Sierra Leone (GoSL) through the Ministry of Health and Sanitation declared an outbreak of EVD in the country following the laboratory confirmation of a suspected case from Kailahun district. As of 20 July 2014 a total number of 409 cases have been confirmed positive for EVD and 139 confirmed deaths in seven districts of Sierra Leone (Kambia, Kailahun, Kenema, Port Loko, Bo, Bonthe and Western Area) but highest in Kailahun (282 Confirmed cases and 97 Confirmed deaths). The GoSL has been working seriously to control the disease but it is spreading continuously [20].

By 22 August 2014, the Ministry of Health and Sanitation of Sierra Leone and WHO reported a cumulative total of 910 suspect and confirmed cases, including 804 laboratory-confirmed cases, and 392 deaths. Cases have been reported from all 12 Sierra Leone districts [11]. By 28 August 2014, the Ministry of Health and Sanitation of Sierra Leone and WHO reported a cumulative total of 1,026 suspect and confirmed cases, including 935 laboratory-confirmed cases, and 422 deaths [49].

The GoSL with WHO has taken 6 (July to December 2014) months of national operational plan. The budget of the Government is estimated to be $\$ 25,817,130$. The amount pledged by partners is $\$ 7,658,180$, by the GoSL is $\$ 10,00,000$ and the current gap is $\$ 8,258,949$ [20].

By 17 September 2014, WHO reported that a total of 1,753 suspected cases and 537 deaths in Sierra Leone [50].

\subsection{Liberia}

On 10 April 2014, in Liberia six cases were confirmed positive of the Ebolavirus and all died at the time. The Ministry of Health and Social Welfare (MoHSW) found a case of a Liberian female who is married to a Sierra Leonean. She was admitted hospital on 23 May, discharged against medical advice on 25 May and died six hours later. Ebolavirus disease has continued to spread in 7 counties are; Bomi, Bong, Grand Gedeh, Margibi, Montserrrado, Lofa and Nimba (of the 15 counties) of Liberia. Six alert counties are; Grand cape Mount, Gbarpolu, Grand Bassa, Rivercess, Sinoe and River Gee. Up to 24 July 2014, 296 infected were recorded with 147 deaths. Already 39 cases have been recorded among health workers with 17 deaths [19].

By 22 August 2014, the MoHSW of Liberia and WHO have reported 1,082 suspect and confirmed EVD cases, including 269 laboratory-confirmed, and 624 deaths. Suspect and confirmed cases have been reported in 11 of 15 Counties [11]. By 28 August 2014, the MoHSW of Liberia and WHO have reported 1,378 suspect and confirmed EVD cases, including 322 laboratoryconfirmed, and 694 deaths [49].

By 17 September 2014, WHO reported that a total of 3,022 suspected cases and 1,578 deaths in Liberia [50].

From onset of the epidemic, a multi-disciplinary National Task Force (NTF) chaired by the MoHSW was re-activated in March 2014 to ensure effective coordination of the response efforts. On 26 July 2014, the
President has declared the EVD epidemic as national health emergency and established National Task Force [19].

Estimated budget for response to the epidemic of Ebolavirus haemorrhagic fever over six months (July to December 2014). Total estimated budget is $\$ 21,430,990$, pledged by partners is $\$ 6,185,830$ and the gap is $\$ 15,245,160$ [45].

\subsection{Guinea}

On 22 March 2014, the Guinea Ministry of Health notified WHO about a rapidly outbreak of EVD [48]. The WHO Regional Office for Africa organized an emergency inter-ministerial meeting in Accra, Ghana, on 2-3 July 2014 to enable Member States and partners to reach consensus on a regional response strategy to halt the epidemic. By 8 July 2014, Guinea had recorded 409 cases of Ebolavirus (296 was confirmed) and 309 deaths [18].

By 22 August 2014, the Guinea Ministry of Health announced 607 suspect and confirmed cases of EVD, including 443 laboratory-confirmed cases, and 406 deaths [11]. By 28 August 2014, the Guinea Ministry of Health announced 648 suspect and confirmed cases of EVD, including 482 laboratory-confirmed cases, and 430 deaths [12].

By 17 September 2014, WHO reported that a total of 965 suspected cases and 623 deaths in Guinea [50].

The highest pandemic area is Guéckédou where 166 cases were confirmed and 132 had died. Other pandemic areas are Macenta, Kissidougou, Conakry, Dabola, Télimélé, Boffa, Dubreka, Djingaraye, Fria, Siguiri, Pita, Nzerekore, Yamou and Kouroussa. Estimated budget for response to the epidemic of Ebolavirus haemorrhagic fever over six months (July to December 2014). Total estimated budget is $\$ 11,131,419$, pledged by partners is $\$ 714,286$ and the gap is $\$ 10,417,133$ [18].

\subsection{Nigeria}

The first reported Ebola case in Nigeria was an imported case of a Liberian-American, Patrick Sawyer, who travelled by air from Liberia and became violently ill upon arriving in the city of Lagos. Sawyer died 5 days later, on 25 July 2014 [2]. On 19 August, it was reported that the doctor who treated Sawyer, Ameyo Adadevoh, had also died of EVD [32]. On 6 August, Nigerian authorities confirmed the Ebola death of a nurse who had also treated Sawyer [26]. By 22 August 2014, the Nigerian Ministry of Health and WHO reported 16 suspect and confirmed cases, including 12 laboratory-confirmed, and 5 deaths [11].

By 17 September 2014, WHO reported that a total of 21 suspected cases and 8 deaths in Nigeria [50].

Government of Nigeria has announced that it is reversing its decision to keep schools closed after the summer holiday until 13 October, in order to halt the spread of Ebola [49].

\subsection{Senegal}

On 30 August 2014, Senegal's Ministry of Public Health and Social Affairs provided WHO with details about a case of EVD announced in that country on 29 August. The case is a 21-year-old male native of Guinea, 
who arrived in Dakar, by road, on 20 August and stayed with relatives at a home in the outskirts of the city. On 23 August, he sought medical care for symptoms that included fever, diarrhoea, and vomiting. He received treatment for malaria, but did not improve and left the facility. On 27 August the person has suspected as EVD patient but he has escaped from hospital. By 17 September 2014, WHO reported that a total of 1 suspected cases and no deaths in Senegal [50].

\section{Recommendations}

Up to redemption of EVD people of different countries should avoid nonessential travel to Guinea, Liberia, Nigeria and Sierra Leone. The healthy citizens of these countries should travel in their own countries very carefully.

Nonessential staff and visitors should be restricted from entering the room of patients with suspected EVD. Limit the number of visitors allowed access to the patient room who take care of the patients and they should immediately after taking care of the patients wash hands and other parts of the body which come contact with the patients with soap, detergent and pure water. All visitors use personal protective equipment according to the health care facility (HCF) guidance. They should maintain adequate distance about $15 \mathrm{~m}$ from the infected patients.

Health care providers should perform hand hygiene before and after direct patient care. They should wear surgical gloves, non-impermeable gown, medical mask and goggles when enter in the patient care area. Never reuse syringes or needles and do not bend, break or otherwise manipulate used needles by hand. Laboratory personnel handling potential EVD clinical specimens should wear gown, gloves, and special respirators. Postmortem examinations should be performed obeying strictly all the rules for EV patients handling.

Persons who die of EVD must be handled using strong protective clothing and gloves. Dead bodies should not be sprayed, washed or embalmed. Only trained personnel should handle dead bodies during the outbreak. Dead bodies should be wrapped in sealed leak-proof material and cremated or buried promptly in a sealed casket.

People of western Africa should not come contact with ill or dead animals (especially primates and bats) and avoid eating of bushmeat.

\section{Concluding Remarks}

In this paper we have tried to represent elementary ideas about the EVD. Although the outbreak of this disease is only in central and western Africa, it may spread worldwide if the social consciousness is not created and proper treatment is not available. After a short period 'the 2014 outbreak' will extinct but in future if the outbreaks occur then they may be more fatal than the present outbreak. Yet there is no proper treatment or medicine and vaccine to cure the patients. The frequent outbreaks may disconnect the people of the effected countries from the rest of the world. Invention of medicine of this fatal disease is necessary to stop the outbreaks of this disease. WHO and other social welfare organizations should create necessary fund for the research of this disease. We hope within short time the recovery medicines of this disease will invent and people will not suffer from this disease.

\section{References}

[1] Baron, R.C., McCormick, J.B. and Zubeir, O.A., "Ebola Virus Disease in Southern Sudan: Hospital Dissemination and Intrafamilial Spread”, Bulletin of the World Health Organization, 1983. 61(6): 997-1003.

[2] BBC News, "Nigeria 'on Red Alert' Over Ebola Death in Lagos, BBC News”, 26 July 2014.

[3] Becker, S., Rinne, C., Hofsass, U., Klenk, H.D. and Muhlberger, E. "Interactions of Marburg Virus Nucleocapsid Proteins", Virology, 1998. 249 (2), 406-417.

[4] Beniac, D.R., Melito P,L., deVarennes, S.L., Hiebert, S.L., Rabb, M.J., Lamboo, L.L., Jones, S.M., and Booth, T.F., "The Organisation of Ebola Virus Reveals a Capacity for Extensive, Modular Polyploidy”, PLoS One, 2012. 7(1), e29608.

[5] Bharat, T.A.M., Noda, T., Riches, J.D., Kraehling, V., Kolesnikova, L., Becker, S., Kawaoka, Y., and Briggs, J.A.G., "Structural Gissection of Ebola Virus and its Assembly Determinants Using Cryoelectron Tomography”, PNAS, USA, 2012. 109 (11): 4275-4280.

[6] Bowen, E.T., Lloyd, G., Harris, W.J., Platt, G.S., Baskerville, A. and Vella, E.E., "Viral Haemorrhagic Fever in Southern Sudan and Northern Zaire”, Preliminary Studies on the Aetiological Agent, Lancet, 1977. i: 571-573.

[7] CDC, "Known Cases and Outbreaks of Ebola Hemorrhagic Fever", Center for Disease Control and Prevention, US Department of Health and Human Services. 2008.

[8] CDC, "Ebola Hemorrhagic Fever Information Packet", Centers for Disease Control and Prevention, US Department of Health and Human Services. 2009.

[9] CDC, "CDC Urges all US Residents to Avoid None-essential Travel to Liberia, Guinea and Sierra Leon Because of an Unprecedented Outbreak of Ebola”, CDC, July 31, 2014. 2014a.

[10] CDC, "Ebola Hemorrhagic Fever", US Department of Health and Human Services. 2014b.

[11] CDC, "Update: 22 August 2014, Ebola Hemorrhagic Fever", Center for Disease Control and Prevention. US Department of Health and Human Services. 2014c.

[12] CDC, "2014 Ebola Outbreak in West Africa, Update: 17 September 2014”, Centers for Disease Control and Prevention, US Department of Health and Human Services. 2014d.

[13] Chepurnov, A.A., Chuev, P., P’Iankov, O.V., Efimova, I.V., “The Effect of Some Physical and Chemical Factors on Inactivation of the Ebola Virus”, Voprosy Virusologii. 1995, 40(2):74-76.

[14] Colebunders, R. and Borchert M., "Ebola Haemorrhagic Fever: A Review”, Journal of Infection, 2000. 40: 16-20.

[15] ECDC, "Outbreak of Ebola Virus Disease in West Africa, European Centre for Disease Prevention and Control”, Third update, 1 August 2014. Stockholm: ECDC; 2014.

[16] Feldmann, H.K., "Molecular Biology and Evolution of Filoviruses”, Archives of Virology Supplementum, 1993. 7: 81-100.

[17] Feldmann, H.K. and Geisbert, T.W. "Ebola Haemorrhagic Fever", The Lancet, 377(9768): 849-862. 2011.

[18] GoG, "Planned Response to the Ebolavirus Disease Epidemic in Guinea, Ministry of Health Republic of Guinea”, July-December 2014. 2014.

[19] GoL, "Liberia Operational Plan for Accelerated Response to Reoccurrence of Ebola Epidemic", Ministry of Health and Social Welfare, July-December 2014. 2014.

[20] GoSL, "Sierra Leone Accelerated Ebolavirus Disease Outbreak Response", Government of Sierra Leone, Ministry of Health and Sanitation, July-December 2014. 2014.

[21] IPAC Guidance, "Infection Prevention and Control Guidance for Patients with Suspected or Confirmed Ebola Virus Disease (EVD) in Ontario Health Care Settings”, Public Health Ontario. 2014.

[22] Jahrling, P.B., Geisbert, T.W., Dalgard, D.W., Johnson, E.D., Hall, W.C. and Peters, C.J. "Preliminary Report: Isolation of Ebola Virus from Monkeys Imported to USA”. Lancet, 335(8688): 502505. 1990. 
[23] Klenk, H.D. and Feldmann, H., "Ebola and Marburg Viruses: Molecular Cellular Biology", British Library Cataloguing-inPublication Data, Garland Science, Horizon Bioscience, Wymondhan UK. 2004.

[24] Kuhn, J.H., Becker, S., Ebihara, H., Geisbert, T.W., Johnson, K.M., Kawaoka, Y., Lipkin, W.I., Negredo, A.I., Nichol, S.T., Peters, C.J., Tenorio, A., Volchkov, V.E. and Jahrling, P.B., "Proposal for a Revised Taxonomy of the Family Filoviridae: Classification, Names of Taxa and Viruses, and Virus Abbreviations", Archives of Virology, 155(12): 2083-2103. 2010.

[25] MacNeil, A., Farnon, E.C., Morgan, O.W., Gould, P., Boehmer, T.K., Blaney, D.D., Wiersma, P., Tappero, J.W., Nichol, S.T., Ksiazek, T.G., and Rollin, P.E., "Filovirus Outbreak Detection and Surveillance: Lessons From Bundibugyo", The Journal of Infectious Diseases, 204: S761-S767. 2011.

[26] Mark, M., "Ebola Outbreak: Nurse who Treated First Victim in Nigeria Dies”, The Guardian, 7 August 2014. 2014.

[27] Mateo, M., Carbonnelle, C., Martinez, M.J., Reynard, O., Page, A., Volchkova, V.A. and Volchov, V.E., "Knockdown of Ebola Virus VP24 Impairs Viral Nucleocapsid Assembly and Prevents Virus Replication”, The Journal of Infectious Diseases, 204 Suppl 3, S892-S896. 2011.

[28] Muhlberger, E., Lotfering, B., Klenk, H.D. and Becker, S., "Three of the Four Nucleocapsid Proteins of Marburg Virus, NP, VP35, and L, are Sufficient to Mediate Replication and Transcription of Marburg Virus-specific Monocistronic Minigenomes”, Journal of Virology, 72(11): 8756-8764. 1998.

[29] Muhlberger, E., Weik, M., Volchkov, V.E., Klenk, H.D. and Becker, S., "Comparison of the Transcription and Replication Strategies of Marburg Virus and Ebola Virus by Using Artificial Replication Systems”, Journal of Virology, 73(3): 2333-2342. 1999.

[30] Nanbo, A., Watanabe, S., Halfmann, P. and Kawaoka, Y., "The Spatio-temporal Distribution Dynamics of Ebola Virus Proteins and RNA in Infected Cells”, Nature, Scientific Report, srep 01206. 2013.

[31] Public Health Agency of Canada, "Ebola Virus, Pathogen Safety Data Sheet-Infectious Substances”, Ottawa: Public Health Agency of Canada. 2010.

[32] Reuters, "Lagos Records Second Ebola Case in Doctor Who Treated Victim: Nigeria Health Minister", 4 August 2014. 2014.

[33] Rollin, P.E., Williams, R.J., Bressler, D.S., Pearson, S., Cottingham, M., Pucak, G., Sanchez, A., Trapper, S.G., Peters, R.L., Greer, P.W., Zaki, S., Demarcus, T., Hendricks, K., Kelly, M., Simpson, D., Geisbert, T.W., Jahrling. P.B., Peters, C.J., and Kssiazek, T.G., "Ebola (subtype Reston) Virus among Quarantined Nonhuman Primates Recently Imported from the Philippines to the United States", The Journal of Infectious Diseases, 179(suppl 1): S108-S114. 1999.

[34] Sanchez, A., Trappier, S.G., Mahy, B.W.J., Peters, C.J. and Nichol, S.T., "The Virion Glycoproteins of Ebolaviruses are Encoded in
Two Reading Frames and are Expressed through Transcriptional Editing”, Proceedings of the National Academy of Sciences (PNAS), USA 93: 3602-3607. 1996.

[35] Sanchez, A., Yang, Z., Xu, L., Nabel, G.J., Crews, T. and Peters, C.J. "Biochemical Analysis of the Secreted and Virion Glycoproteins of Ebolavirus”, Journal of Virology, 72: 6442-6447. 1998.

[36] Sullivan, N., Yang, Z.Y. and Nabel, G.J., "Ebola Virus Pathogenesis: Implications for Vaccines and Therapies”, Journal of Virology, 77(18): 9733-9737. 2003.

[37] Volchkov, V.E., Becker, S., Volchkova, V.A., Ternovoj, V.A., Kotov, A.N., Netesov, S.V. and Klenk, H.D. "GP mRNA of Ebolavirus is Edited by the Ebolavirus Polymerase and by T7 and Vaccinia Virus Polymerases”, Virology, 214: 421-430. 1995.

[38] Watanabe, S., Takada, A., Watanabe, T., Ito, H., Kida, H. and Kawaoka, Y., "Functional Importance of the Coiled-coil of the Ebolavirus Glycoprotein”, Journal of Virology, 74: 10194-10201. 2000.

[39] Waterman, T., “Ebola Cote D'Ivoire Outbreaks”, Stanford University. 1999.

[40] WHO, "Ebola Hemorrhagic Fever in Sudan, 1976, Report of a WHO/International Study Team", Bulletin of the World Health Organization, 56(2): 247-270. 1978a.

[41] WHO, "Ebola Hemorrhagic Fever in Zaire, 1976, Report of an International Commission", Bulletin of the World Health Organization, 56(2): 271-293. 1978b.

[42] WHO, "End of Ebola Outbreak in Uganda (Press Release)", World Health Organization, 20 February 2008. 2008a.

[43] WHO, "Interim Infection Control Recommendations for Care of Patients with Suspected or Confirmed Filovirus (Ebola, Marburg) Hemorrhagic Fever", DP/EPR/WHO, Geneva March 2008. 2008b.

[44] WHO, "Ebola Virus Disease Fact Sheet No. 103”, World Health Organization, March 2014. 2014a.

[45] WHO, "WHO Strategic Action Plan for Ebola Outbreak Response”, July-December 2014. 2014b.

[46] WHO, "WHO Statement on the Meeting of the International Health Regulations Emergency Committee Regarding the 2014 Ebola Outbreak in West Africa”, WHO Statement, 8 August 2014. 2014c.

[47] WHO, "Frequently Asked Questions on Ebola Virus Disease", Updated 8 July 2014. 2014d.

[48] WHO, "Ebola Virus Disease in Guinea-23 March 2014”, Geneva: WHO; 2014. 2014e.

[49] WHO, "Ebola Virus Disease, West Africa-Update 28 August 2014", Epidemic \& Pandemic Alert and Response (EPR)Outbreak News (WHO). 2014f.

[50] WHO, "Ebola Death Toll Passes 1,900, Says WHO”, BBC News 17 September 2014. 2014g.

[51] Wikipedia (20140, The Free Encyclopedia, 2014 West Africa Ebola Virus Outbreak. 